\title{
PRONATEC FIC: UMA AVALIAÇÃO DA EFICIÊNCIA, EFICÁCIA E DA EFETIVIDADE DOS CURSOS OFERECIDOS PELO PROGRAMA.
}

\author{
Janilson Gomes da Fonseca, Maria Aparecida Ferreira dos Santos \\ Instituto Federal de Educação, Ciência e Tecnologia do Rio Grande do Norte \\ DOI: 10.15628/rbept.2018.xxxx
}

Artigo submetido em out/2018 e aceito em jan/2019

\begin{abstract}
RESUMO
O presente texto visa fazer uma avaliação ex post ou avaliação de resultados da política publicado Pronatec, dando foco aos cursos FIC. Para tanto, cotejá-la com as fases do ciclo das políticas públicas: a agenda, a implementação e a avaliação, com foco nesta última, tendo como pano de fundo, os critérios da eficiência, da eficácia e da efetividade. A hipótese levantada é de que tais critérios não foram alcançados por essa Política pública no que diz respeito às satisfações das necessidades dos trabalhadores (as) e da sociedade. Trata-se de pesquisa qualitativa, exploratória, descritiva e documental. A metodologia utilizada foi revisão bibliográfica em alguns autores e também em legislações e sites pertinentes ao tema com o uso de fontes primárias e secundárias. O resultado alcançado foi à confirmação da hipótese levantada com relação aos benefícios não contemplados pelo Programa.
\end{abstract}

Palavras-Chave: Pronatec FIC. Avaliação. Eficiência. Eficácia.Efetividade.

\section{PRONATEC FIC: A STUDY OF THE EVALUATION OF THE EFFICIENCY, EFFECTIVENESS AND EFFECTIVENESS OF THE COURSES OFFERED.}

\begin{abstract}
The present text aims to make an ex post evaluation or evaluation of results of the Pronatec public policy, giving focus to the FIC courses. To do so, compare it with the phases of the public policy cycle: the agenda, implementation and evaluation, focusing on the latter, against the background of the criteria of efficiency, effectiveness and effectiveness. The hypothesis raised is that such criteria were not achieved by this public policy regarding the satisfaction of the needs of workers and society. It is qualitative, exploratory, descriptive and documentary research. The methodology used was a bibliographical review in some authors and also in legislation and sites pertinent to the theme with the use of primary and secondary sources. The result achieved was the confirmation of the hypothesis raised regarding the benefits not contemplated by the Program.
\end{abstract}

Keywords: Pronatec FIC. Evaluation. Efficiency. Effectiveness. Effectiveness. 


\section{INTRODUÇÃO}

A partir dos anos de 1990, no governo de Fernando Henrique Cardoso - FHC, (1995-2003), no Brasil se iniciava uma mudança de paradigma no regime capitalista de acumulação do capital, de descentralização das políticas públicas e reestruturação produtiva do capital ou Toyotismo.

Com essa mudança do regime capitalista Taylorista/Fordista ${ }^{1}$ para o de acumulação flexível, de privatizações e parcerias com o setor privado, a educação de um modo geral, teve que adaptar-se a essa nova realidade para atender a novas demandas oriundas do mundo do trabalho, sofrendo influências diretas na educação em geral e especificamente na qualificação profissional.

As consequências das influências nas mudanças na educação e especificamente na qualificação profissional, principalmente a qualificação individual, também passou a ser mais uma mercadoria de consumo na lógica da acumulação capitalista, onde a venda e a compra se movimentam sob a égide da ideologia da empregabilidade.

Também marcado pela reforma de administração do Estado², que nesse contexto, adotou-se no país o modelo gerencial de gestão pública, cujos princípios da administração privada são transferidos para a pública.

Enquadra-se como modelos gerenciais, segundo Secchi (2014, p. 155):

A Nova Gestão Pública (new public management) e o governo empreendedor (EntrepreneurialGovernment). Entre os princípios do Modelo Gerencial, está a eficácia, a liberdade de decisão do gestor, a orientação a resultados, a orientação às necessidades dos

\footnotetext{
${ }_{1}^{1}$ Para Harvey, a data oficial simbólica do Taylorismo Fordismo, ocorreu em 1914, quando Henry Ford introduziu seu dia de oito horas e cinco dólares como recompensa para os trabalhadores da linha de montagem de automóveis [...] aliado com a contribuição de F.W. Taylor, com os princípios da administração cientifica publicado em 1911, um influente tratado que descrevia como a produtividade poderia ser radicalmente aumentada por meio da decomposição de tarefas, seguindo padrões rigorosos de tempo e estudo de movimentos [...].(HARVEY,1993, p.120).

2 Segundo Dourado (2001, p.235/36) "A defesa ideológica dessa reforma é implementada pelo discurso de modernização e racionalização do Estado, objetivando, desse modo, a superação das mazelas do mundo contemporâneo [...] e de adaptação às novas demandas pelo processo de globalização em curso".
} 
usuários dos serviços públicos, e a competição intra e interorganizacional.

Foi com o plano diretor da reforma do Estado (PDRAE), que foi instituído a nova gestão pública no Brasil, cujos princípios da legalidade, impessoalidade, moralidade, publicidade e eficiência, inseridas no artigo 37 da CF /1988, fazem parte desse novo modelo de gestão e estão dispostos na lei da seguinte forma: "A administração pública direta e indireta de qualquer dos Poderes da União, dos Estados, do Distrito Federal e dos Municípios obedecerá aos princípios de legalidade, impessoalidade, moralidade, publicidade e eficiência [...]" (BRASIL, 1988).

A eficiência consiste aos usos dos recursos relacionados com os serviços disponibilizados aos beneficiários das políticas; a eficácia é critério de avaliação de atingimento de metas estabelecida na política e a efetividade, aos resultados em termos de bem-estar para os beneficiários da política pública e da sociedade como um todo. Ou seja, a efetividade é a junção da eficiência com a eficácia (CASTRO, 2006).

Ou dito com outras palavras, conforme Silva (2001, p.47), "eficiência ou rentabilidade econômica é a relação entre os custos despendidos e os resultados do programa; eficácia é o grau em que os objetivos e metas foram alcançados na população beneficiária e, efetividade, a relação entre os resultados e objetivos".

No que tange à Educação Profissional, utilizando-se dos conceitos de eficiência, eficácia e efetividade, Dornelles (2011) recorrendo a Belloni (et. al, 2003), especifica essas definições nesse âmbito. Para a autora:

A eficácia, portanto, refere-se basicamente à qualidade dos processos educacionais; a eficiência, à qualidade somada a otimização dos recursos, abrangendo inclusive a articulação entre as políticas; e sobre a efetividade a autora estende o conceito à efetividade social, que no caso da educação profissional relacionase aos resultados provocados na vida do trabalhador (2011, p.30).

Com as novas emergências demandadas do setor produtivo, faz-se necessário que o Estado, por meio de políticas públicas de qualificação profissional em massa, atenda as essas novas necessidades sociais a partir de identificações de problemas sociais, no tocante ao desemprego em massa 
ocasionado pela estrutura do novo modelo de regime de acumulação do capital no País. Assim, emergiram, também, supostas soluções para resoluções desses problemas.

Destarte, foram instituídos, desde a década de 90, entre outros programas e planos de qualificação profissional em massa, os planos: Plano Nacional de Qualificação do trabalhador (PLANFOR), implantado a partir de 1990; o Plano Nacional de Qualificação (PNQ), em vigor a partir de 2003 e o Programa Nacional de acesso ao ensino técnico e emprego (PRONATEC), instituído em 2011; executados nos governos de FHC, Lula e Dilma, respectivamente.

É sobre a política pública de Educação Profissional do PRONATEC que essa pesquisa se debruçará, objetivando fazer uma avaliação ex post, (posto que já ocorreu a implementação) e, atualmente, encontra-se no limbo diante do atual momento de indefinição na política nacional.

Esse Programa foi instituído pela lei 12.513 de 26 de Outubro de 2011, executado pela União, com a finalidade de ampliar a oferta de educação profissional e tecnológica por meio de programas, projetos e ações de assistência técnica e financeira. O PRONATEC tem como objetivos principais: expandir, interiorizar e democratizar a oferta de cursos de educação profissional técnica de nível médio presencial e a distância e de cursos e programas de formação inicial e continuada ou qualificação profissional; fomentar e apoiar a expansão da rede física de atendimento da educação profissional e tecnológica; contribuir para a melhoria da qualidade do ensino médio público, por meio da articulação com a educação profissional. $^{3}$

$\mathrm{Na}$ perspectiva metodológica, a pesquisa é analítica de caráter bibliográfica, exploratória e documental com abordagem qualitativa conduzida pelo referencial teórico sócio crítico.

\footnotetext{
${ }^{3}$ Disponível em: http://portal.mec.gov.br/pronatec 


\section{DISCUSSÕES E RESULTADOS}

Segundo Secci (2014), o termo "política" na língua portuguesa, pode assumir duas conotações básicas, que as comunidades epistêmicas de países de língua inglesa as diferenciam usando os termos politics e policy. Para esse autor, baseado na concepção de Bobbio (2002), "politics, é a atividade humana ligada à obtenção e manutenção dos recursos necessários para o exercício do poder sobre o homem" (SECHHI, 2014, p.1). Esse sentido da palavra "política" nas pessoas que falam o português seja o mais presente no imaginário coletivo: o de atividade de competição política.

O Segundo sentido da palavra do termo "política", para o autor, é expresso pela palavra policy em inglês. Essa dimensão do termo política é a mais consistente e a que se relaciona com a orientação para a tomada de decisões e ações. O termo Política pública (PP) (publicpolicy) completa o autor, vincula-se ao segundo sentido da palavra "política". Políticas públicas tratam-se, portanto, "do conteúdo concreto e do conteúdo simbólico de decisões políticas, e do processo de construção e atuação dessas decisões". (SECHI, 2014, p.1).Ou seja, uma política pública é um procedimento elaborado para enfrentar um problema público.

Nela se encontra dois elementos principais: intencionalidade pública e resposta a um problema público. O motivo para implementação de uma Política pública é o tratamento ou a resolução de um problema relevante socialmente. Como exemplo, a qualificação em massa de trabalhadores (as) para atender as novas demandas do capital ou para suprir o suposto "apagão de mão de obra" que fora propagado durante o lançamento do Pronatec pela presidente Dilma Rousseff em 2011.

Em que pese tais definições, o autor alerta que qualquer definição de políticas públicas é arbitrária e que na literatura especializada não há consenso em torno dessa definição em razão de disparidades de respostas referentes a questionamentos básicos. A saber: "A) políticas públicas são elaboradas exclusivamente por atores estatais? B) Políticas públicas se referem à omissão ou a negligencia? C) Apenas diretrizes estruturantes (de nível estratégico) são políticas públicas"? (SECHI, 2014, p.2). 
Diante dessa afirmação de arbitrariedade acerca do conceito, Souza (2007, p. 68) corrobora essa opinião que não existe uma única, nem melhor definição sobre o que seja política pública. Sendo assim, discorre sobre alguns autores que tratam da temática com suas definições.

Resumidamente:

Dye (1984) o que o governo escolhe fazer ou não fazer. $E$ a definição mais conhecida continua sendo a de Laswell (1988), ou seja, decisões e análises sobre política pública implicam responder às seguintes questões: quem ganha o que? Por que e que diferença faz?"(SOUZA, 2007, p.68).

Como visto, no geral, as Políticas Públicas têm o papel fundamental nas soluções de problemas emanados socialmente. É o Estado em ação. É o estado implantando um projeto de governo, por meio de programas, de ações direcionadas para setores específicos da sociedade. Como exemplo de algumas das ações no campo da qualificação profissional, a implementação do PRONATEC-FIC na contemporaneidade. No entanto, muitas dessas definições desprezam a essência das políticas públicas, o embate e conflitos dos atores em torno de ideias e interesses nas formulações e prioridades na agenda governamental.

A seguir, far-se-á uma breve explanação acerca do ciclo de políticas públicas (polycycycle), que consiste no processo de elaboração das políticas públicas, pontuando brevemente alguns de seus elementos, embora o foco da pesquisa recaia sobre a avaliação.

\section{CICLO DAS POLÍTICAS PÚBLICAS}

De acordo com Secchi (2014, p. 43), o ciclo das políticas públicas "é um esquema de visualização e interpretação que se organiza em fases sequenciais e interdependentes". Para o autor, consiste nas seguintes fases: Identificação do problema; formação da agenda; formulação de alternativas; tomada de decisão; implementação; avaliação e extinção. O autor observa que embora a importância heurística, esse ciclo raramente reflete a real 
dinâmica do seu processo, as fases se apresentam misturadas e as sequências se alternam no decorrer do processo.

Para Souza (2007, p.74), "esta tipologia vê a política pública como um ciclo deliberativo, formado por vários estágios e construindo um processo dinâmico e de aprendizado". A autora define o ciclo constituindo das seguintes fases: definição da agenda, identificação de alternativas, avaliação das opções, seleção das opções, implementação e avaliação.

Em ambas as definições, o ciclo não necessariamente ocorre nessa ordem em que se apresentam. Porque raramente traduz o movimento real, pois as fases ora se alternam, ora se misturam em decorrência das disponibilidades de recursos ou dos sujeitos envolvidos durante o seu processo.

\subsection{A AGENDA DAS POLÍTICAS PÚBLICAS}

A gênese de uma Política Pública se dá a partir da definição da agenda de um governo que se forma baseados em alguns critérios: a relevância do problema a ser resolvido; o reflexo do problema na política global do governo, os benefícios trazidos com a solução do problema e aos momentos favoráveis para a solução de um determinado problema (DORNELLES, 2011).

Na concepção de Secchi, (2014, p.46. Grifos nosso.), corroborando essa definição:

\footnotetext{
Agenda é um conjunto de problemas ou temas entendidos como relevantes. Ela pode tomar forma de um programa de governo, um planejamento orçamentário, um estatuto partidário ou, ainda, de uma simples lista de assuntos que o comitê editorial de um jornal entende como importantes.
}

A imprensa e/ou a grande mídia exerce uma grande influência na definição da agenda política, em razão da lista de problemas que são recepcionadas atenciosamente pelos diversos meios de comunicação de massa.

Ainda para o autor, existem dois tipos de agenda. A saber: 
I) Agenda Política: esta, também conhecida como agenda sistêmica. Refere-se ao conjunto de problemas ou temas que a classe política percebe como merecedora de intervenção pública; e II) Agenda formal ou agenda institucional: é a que elenca os problemas ou temas que o poder público já decidiu enfrentar. (SECCHI, 2014, p.46).

A prioridade da agenda se dá a partir da identificação de um problema público. Um problema público por sua vez, é a diferença entre a situação atual e uma situação ideal possível. Ou seja, quando a situação atual é considerada como inadequada e quando há uma perspectiva de se alcançar uma situação melhor no que tange às questões públicas. Um problema só se torna de fato público quando os atores políticos envolvidos o percebem intersubjetivamente como um problema. Dessa maneira, o problema percebido poderá ou não entrar na pauta da agenda pública e poderá ou não se transformar em uma política pública através de sua implementação.

O PRONATEC entrou na agenda governamental e foi implementado no primeiro ano do governo de Dilma Rousseff em 2011. Entrou em vigor sob o discurso da falta da mão de obra qualificada nesse mesmo ano. No discurso de lançamento da então presidente, o qual foi divulgado no portal do planalto, afirma que, "em [...] alguns casos, falta mão de obra qualificada, em outros sobra mão de obra sem a qualificação necessária derivada das nossas necessidades, da indústria, do comércio dos serviços, enfim, do sistema produtivo". (BRASIL, 2011). Justifica-se dessa forma, portanto, o discurso da necessidade da qualificação profissional.

Para Frigotto (2013), a metáfora do apagão para o autor, que reclama a falta de trabalhadores(as) qualificados(as), é difundida por empresários e seus representantes intelectuais e do cenário político, cujo discurso esconde quem a produze decorre da mentalidade colonizadora e escravocrata da classe detentora dos meios de produção. Assim, para o autor:

Os dados da Pnad mostram que apenas 9\% dos jovensentre 18 e 24 anos entram no curso superior. É claro que vão faltar, especialmente em algumas áreas, profissionais qualificados. Como nos últimos cinquenta anos avançamos de forma pífia no aumento quantitativo e na qualidade de jovens que cursam o ensino médio na idade adequada, a maioria só atinge o ensino fundamental, e as políticas de formação profissional para grande massa de jovens e 
adultos estão na lógica da improvisação, da precarização e do adestramento (FRIGOTTO, 2013).

O autor observa ainda que na essência desse suposto apagão, encontram-se problemas educacionais anteriores, em que grande parte de jovens não encontram condições existenciais adequadas para finalizar 0 ensino básico, tampouco ingressar no superior.

Destarte, retoma-se a teoria do capital humano preconizada por Shultz (1973), a qual preconiza de maneira linear, a relação entre educação, treinamento e desenvolvimento. E sob a égide dessa teoria, repousa o discurso da empregabilidade, esta consiste em uma nova versão daquela e representa uma categoria significativa da lógica do Toyotismo, direcionam-se às práticas ideológicas das políticas de formação profissional ou qualificação profissional.

Nesse sentido, de acordo com Alves (2007), atualmente, a empregabilidade tornou-se senso comum nas ideologias de qualificação profissional no capitalismo global. Conforme o autor:

a educação ou a aquisição (consumo) de novos saberes, competências e credenciais apenas habilitam o individuo para a competição num mercado de trabalho cada vez mais restrito, não garantindo, portanto, sua integração sistêmica plena (e permanente) à vida moderna. Enfim, a mera posse de novas qualificações não garante ao individuo um emprego no mundo do trabalho (2007, p. 251).

Dessa forma, desprovidos de oportunidades e escolhas, os trabalhadores (as) e filhos de trabalhadores (as) optam por fazer cursos de qualificação profissional aligeirados, superficiais e descolados de qualquer possibilidade de aumento de escolaridade, cujas aquisições de certificados em um mercado cada vez mais competitivo, não garantem a inserção no mundo do trabalho.

Há nesse contexto, portanto, um mascaramento da realidade por meio desse discurso, uma vez que ignora o processo histórico de desigualdade social no País. Além disso, o Estado, por meio desse discurso, enviesado pela ideologia neoliberal, se exime de responsabilidades de provedor de oportunidades de postos de trabalho e transfere a culpa para o trabalhador 
por estarem desempregados e lou mal empregados, e ainda, a responsabilidade de seu sucesso ou fracasso em suas vidas profissionais.

É nesse cenário que a Política Pública do Pronatec entrou na agenda governamental e implementada nessas bases.

\subsection{IMPLEMENTAÇÃO DA POLÍTICA PÚBLICA}

A implementação de uma política pública vem após a tomada de decisão da contemplação da agenda, ou seja, de sua formulação e antecede as primeiras intenções e esforços avaliativos.

De acordo com Dornelles (2011,), “a implementação constitui-se da execução de atividades com vistas ao alcance das metas estabelecidas na formulação. Assim, se afere o grau de eficiência e eficácia dos programas ou políticas públicas" (2011, p.23). A autora observa ainda que, considerando essa etapa do ciclo não como uma parte posterior a formulação, mas como um processo no qual as decisões são tomadas e não apenas executadas, de que a implementação aliada à avaliação pode ser geradora de informações e aprendizado.

Dessa maneira, a participação efetiva dos atores políticos e sociais, como os trabalhadores representados pelos sindicatos, os movimentos sociais, os empresários, os políticos, os partidos políticos, os stakeholders ${ }^{4}$, entre outros, no processo de formulação e implementação, poderá dar sustentabilidade e legitimidade à política pública. Esse jogo consiste em ações fundamentais para a consolidação da democracia. O momento da implementação, portanto, é aquele que administração pública assume a sua função precípua: a de execução das políticas públicas.

Apesar de o PRONATEC ter sido instituído em 2011, observa-se que a responsabilidade de qualificação dos trabalhadores já vinha sido terceirizada e executada por instituições privadas, principalmente pelo sistema $S^{5}$, com

\footnotetext{
${ }^{4}$ Entende-se por stakeholders pessoa ou grupo que possui participação, investimentos ou ações e que possui interesse e um uma determinada empresa ou negócio. Também pode significar partes interessadas, sendo pessoas ou organizações que podem ser afetadas pelos projetos e processos de uma organização.

${ }^{5}$ O sistema S é formado por: Serviço Nacional de Aprendizado Comercial ( SENAC ); Serviço Nacional de Aprendizado Industrial ( SENAI ); Serviço Social da Indústria ( SESI ); Serviço 
repasses de recursos oriundos do erário. E quando se terceiriza um serviço de educação, a qualidade se mantém? E os interesses e as pretensões também? Na aparência, para o programa sim, mas, será que na essência os resultados traduzidos em benefícios para a população foram alcançados?

De acordo com o Ministério da Educação e Cultura (MEC), o PRONATEC tem como objetivo de expandir, interiorizar e democratizar a oferta de cursos de educação profissional e tecnológica no país. Buscou ampliar as oportunidades educacionais e de formação profissional qualificada aos jovens, trabalhadores e beneficiários de programas de transferência de renda. Afirma também que de 2011 a 2014, por meio do Programa, foram realizadas mais de 8,1 milhões de matrículas, entre cursos técnicos e de qualificação profissional, em mais de 4.300 municípios e em 2015, foram 1,3 milhão de matrículas (BRASIL, 2011).

Ora, em termos de eficácia, eficiência e efetividade (critérios fundantes para se avaliar uma Política Pública) será que esses objetivos foram de fato alcançados?. Considerando, como visto que a eficácia se refere à qualidade dos processos educacionais; a eficiência, à qualidade somada a otimização dos recursos que abrange inclusive a articulação entre as políticas e, lembrando, que os recursos são escassos e que devem ser utilizados da melhor forma possível; e acerca da efetividade, amplia-se o conceito à efetividade social, que no caso da educação profissional relaciona-se aos resultados provocados na vida do trabalhador e no impacto positivo na sociedade enquanto fomentadora de empregos e renda.

\subsection{AVALIAÇÃO DE POLÍTICA PÚBLICA}

As pessoas, grupos ou governos, quando detectam algum problema, buscam informações para uma tomada de decisão para resolvê-lo. Quando das execuções das ações consideradas oportunas para aquele momento específico, é costumeira umareflexão sobre os acertos e os erros após o processo de execução dessas medidas. Dessa maneira, está ocorrendo uma

Social do Comércio ( SESC ); Serviço Nacional de Aprendizagem Rural ( SENAR ); Serviço Nacional de Aprendizagem do corporativismo ( SESCOOP) e Serviço Social do Transporte ( SEST). Disponível em: https://www12.senado.leg.br/noticias/glossario-legislativo/sistema-s 
avaliação de ações e adquirindo informações para ajustes futuros. Enquanto em Política Pública, Conforme Cohen e Franco (2013), há distintos modelos de avaliação dependendo do objeto a ser avaliado, assim como da formação acadêmica daqueles que executam essa tarefa. Entretanto para os autores,

\begin{abstract}
a constante é, por um lado, a pretensão de comparar um padrão almejado [...] com a realidade [...] e, por outro lado, a preocupação em alcançar eficazmente os objetivos propostos. " avaliar é fixar o valor de uma coisa; para ser feita se requer um procedimento mediante o qual se compara aquilo a ser avaliado com um critério ou padrão determinado" [...]. (2013, p.73. Grifos nossos).
\end{abstract}

Os autores elencam outras definições de outros autores. A saber: "a avaliação foi definida como aquele ramo da ciência que se ocupa da análise da eficiência; ou que a avaliação mede até que ponto um programa alcança certos objetivos" (2013, p.73). Alcançar objetivos, nesse sentido, refere-se à eficácia da Política pública.

Enquanto para Secchi (2013, p.62), com base em Anderson, (1979), a avaliação de Política Pública é o "processo de julgamentos deliberados sobre a validade de propostas para a ação pública, bem como sobre o sucesso ou a falha de projetos que foram colocados em pauta". O autor completa que a partir dessa definição, observa-se a distinção entre avaliação ex ante anterior à implementação - e a avaliação ex post - a que o corre posterior à implementação.

Com relação à pretensão de comparar um padrão almejado com a realidade atual, no caso do PRONATEC-FIC, infere-se que, com base no discurso do apagão de mão de obra, proferido em 2011, seria o de qualificar em massa os jovens e trabalhadores (as) desprovidos de empregos e de renda, já que o problema identificado foi o tal apagão para que esses, uma vez qualificados, obtivessem oportunidade de inserção no mundo do trabalho. Entretanto, isso não reflete a realidade. Pois a Política pública visualizava apenas a aparência da situação e não sua essência.

Trazendo esses esclarecimentos para a atualidade, cotejando com as estatísticas de desocupados no País, de acordo com o instituto brasileiro de geografia e estatística (IBGE), no trimestre de setembro a novembro de 2017 , 
havia aproximadamente 12,6 milhões de pessoas desocupadas no Brasil. Confrontando com o mesmo período em 2016 , quando havia 12,1 milhões, houve um crescimento de 3,6\% ou seja, mais de439 mil homens e mulheres desocupadas na força de trabalho. (BRASIL, 2017).

Em outras palavras, a qualificação em massa de brasileiros não surtiu efeito esperado. O de ocupar os desempregados por meio de qualificação profissional via PRONATEC. De 2012 a 2017, com base na Pnad contínua do IBGE, esses índices só aumentaram nos trimestres durante esse período, conforme quadro abaixo:

\begin{tabular}{|l|c|c|c|c|c|c|}
\hline & 2012 & 2013 & 2014 & 2015 & 2016 & 2017 \\
\hline Dez, Jan, Fev & NT & 7,7 & 6,8 & 7,4 & 10,2 & 13,2 \\
\hline Mar, Abr, Mai & 7,6 & 7,6 & 7,0 & 8,1 & 11,2 & 13,3 \\
\hline Jun, Jul, Ago & 7,3 & 7,1 & 6,9 & 8,7 & 11,8 & 12,6 \\
\hline Set, Out, Nov & 6,8 & 6,5 & 6,5 & 9,0 & 11,9 & 12,0 \\
\hline
\end{tabular}

Quadro I - Taxa de desocupação - Brasil - 2012 a 2017.

Fonte: IBGE/Pnad contínua (2017). Adaptado.

Esse contingente, somado aos que trabalham menos do que poderiam, aos que atuam na informalidade e aos que já desistiram ou se desencantaram com a possibilidade de conseguir emprego, os desalentados, portanto, é muito maior do que os números oficiais mostrados acima e serve como exército de reserva em prol do capital e também, para pressionar para baixo os salários dos que estão empregados.

Resta claro, portanto, que de 2012 para 2017 só houve crescimento de desocupados no País, contrariando na essência, os objetivos do programa.

A avaliação de uma política pública compreende a identificação de indicadores, padrões e critérios. Segundo Secchi (2013, p. 63), "os critérios são mecanismos lógicos que servem como base para escolhas ou julgamentos". Baseiam-se em concepções valorativas da realidade e abastecem o avaliador de parâmetros para que forme juízo se uma política pública funcionou a contento ou não. O autor enfatiza que os principais critérios usados para a avaliação são: 
Economicidade refere-se ao nível de utilização de recursos (imputs); produtividade refere-se ao nível de saída de um processo (ouputs); eficiência econômica trata da relação entre outputs (produtividade e imputs (recursos utilizados); [...] eficácia, corresponde ao nível de alcance de metas ou objetivos preestabelecidos. (SECCHI, 2013).

$\mathrm{Na}$ perspectiva da avaliação, as políticas públicas, conforme Silva (2001, p.47), "são decisões governamentais que geram impacto tangível e mensurável ou substantivo, alterando as condições de vida de um grupo ou população ou produzindo mudanças em atitudes, comportamentos e opiniões". Nesse sentido, para a autora, o escopo principal das pesquisas avaliativas consiste em verificar os cumprimentos do objetivo ou de impacto que se traduz no resultado do programa, observando os critérios da eficiência, eficácia e a efetividade.

Nota-se que as definições mencionadas, quase todas se referem aos critérios de eficiência e eficácia como elementos fundantes na avaliação visando à verificação de sua efetividade.

Seguindo na análise, para auxiliar nessa reflexão, tendo como pano de fundo a implementação do PRONATEC, visando à obtenção de respostas a esse questionamento e aos outros de uma das definições de políticas públicas acima mostradas: por que foi criado, que diferença fez na vida dos trabalhadores e quem ganhou com a implementação destas? Recorrer-se-á a Melo (2015), a qual visando desvelar a essência dos objetivos do Programa e suas relações com a expansão, a privatização e a qualidade da Educação Profissional no Brasil, elaborou um estudo em que se levantaram, entre outras análises, as quantidades de vagas ofertadas por meio do Pronatec de 2011 a 2014; a distribuição aproximada de matrículas nos cursos técnicos e FIC do Pronatec. Aqui, pretende-se deter apenas no aspecto quantitativo dos cursos FIC(formação inicial e continuada), abrindo mão dos cursos técnicos, divulgados oficial e extraoficialmente nos números alcançados de matrículas e no montante de recursos utilizados durante o processo de implementação do Programa.

Assim, utilizando-se de fonte secundária dos autores Melo e Moura (2016), no quadro abaixo, mostra-se a distribuição das matrículas nos cursos FIC do Pronatec 2011 a fevereiro de 2015, nos setores públicos e privados. 


\begin{tabular}{|c|c|c|}
\hline OFERTANTE & PORCENTAGEM & MATRÍCULAS \\
\hline Rede Federal & $8 \%$ & 448.000 \\
\hline Rede Estadual & $2 \%$ & 112.000 \\
\hline SENAI & $48 \%$ & 2.688 .000 \\
\hline SENAC & $38 \%$ & 2.128 .000 \\
\hline Outros & $4 \%$ & 224.000 \\
\hline Total & $100 \%$ & 5.600 .000 \\
\hline
\end{tabular}

Quadro II - Distribuição aproximada de matrículas nos Cursos FIC do Pronatec de 2011 à Fevereiro de 2015.

Fonte: Melo e Moura (2016), adaptado.

Observa-se que no quadro acima, que as ofertas dos cursos FIC, corroborando o fato da terceirização da qualificação profissional, onde reside/residiu a maior quantidade de matrículas via Pronatec, está concentrada na esfera privada, principalmente, no sistema S. Prosseguindo na análise, os autores observam que comparando entre a esfera pública e a privada, a pública oferta $46 \%$ dos cursos técnicos, e apenas $10 \%$ dos cursos FIC. Já a privada, oferta $54 \%$ dos cursos técnicos e $90 \%$ dos cursos FIC. E, acerca da expansão da Educação profissionalvia pronatec, os autores observaram que sua prioridade são os cursos FIC oferecidos pelo sistema S e demais instituições privadas (2015, p. 100). O sistema S constitui-se na maior organização brasileira direcionada à educação profissional inserido nesse contexto de fortalecimento mercantilista da qualificação por meio do Pronatec.

Enquanto ao montante dos recursos destinados ao programa, por causa da oferta da bolsa formação que são recursos direcionados às empresas visando à manutenção dos cursos do Pronatec, ainda segundo os autores, parte desse recurso é destinado ao aluno, o que serve de atração para um grande contingente da população participante de programas como bolsa família. Sendo assim, para Melo e Moura:

Esse aspecto sinaliza para a tendência de manutenção da condição subalterna dessa população, atenuando as legitimas necessidades da classe trabalhadora por educação, por meio de respostas 
pragmáticas, como os cursos de curta duração que retomam perspectivas duais da EP (2016, p. 113).

São esses sujeitos que estão matriculados nos cursos FIC, oferecidos pela iniciativa privada, em particular no sistema $S$, com recursos públicos, o que reitera a máxima da educação pobre para os pobres com cursos aligeirados, superficiais, destinados a uma suposta instrumentalização técnica para o atendimento imediato do capital.

Atraídos pelo discurso da empregabilidade, esses sujeitos, sem opções historicamente de uma educação de qualidade que os prepare para a vida e para o mundo do trabalho, optam por essas ofertas de cursos rápidos com a ilusão de que estes irão contribuir, como diferencial, para sua inserção no chamado mercado de trabalho.

\begin{tabular}{|c|c|c|c|}
\hline $\begin{array}{c}\text { Instituições } \\
\text { ofertantes }\end{array}$ & Cursos FIC & Técnicos $^{\mathbf{6}}$ & Total \\
\hline SENAI & $\mathbf{9 7 8 . 1 8 9}$ & 173.792 & 1.151 .981 \\
\hline SENAC & $\mathbf{7 8 1 . 6 3 3}$ & 78.995 & 860.628 \\
\hline SENAT & $\mathbf{1 3 3 . 0 5 8}$ & 247 & 133.305 \\
\hline SENAR & $\mathbf{8 2 . 3 1 3}$ & - & 82.313 \\
\hline Rede privada & - & 292.550 & 292.550 \\
\hline Rede Federal & $\mathbf{4 2 5 . 4 8 2}$ & 21.831 & 447.313 \\
\hline Rede Estadual & $\mathbf{9 9 . 0 3 8}$ & 54.277 & 153.315 \\
\hline Rede Municipal & - & 462 & 462 \\
\hline Total geral & $\mathbf{2 . 4 9 9 . 7 1 3}$ & 622.154 & 3.121 .867 \\
\hline
\end{tabular}

Quadro III - Beneficiários do Pronatec Bolsa-Formação, por rede ofertante e por Cursos FIC e Técnicos de 2011 a Maio de 2014.

Fonte: Melo e Moura (2016, p.113. Grifos nosso).

Os autores observam que de acordo com os dados do relatório de Gestão do exercício de 2013 da SETEC/MEC, deixam claro que a maioria das bolsas financiadas pelo Pronatec concentram-se nos cursos FIC oferecidos pelo setor privado, chegando a $80 \%$, sobretudo, pelo sistema S,

\footnotetext{
${ }^{6}$ Os dados dos recursos destinados aos cursos técnicos nesse quadro originado da pesquisa de Melo e Moura (2016) serve apenas para efeito de comparação com os oferecidos nos cursos FIC, porquanto, o foco desta pesquisa se concentra no Pronatec FIC.
} 
que abarcou o montante de $70,6 \%$ dessas ofertas. Ou seja, a maioria dos cursos oferecidos pelo Pronatec é de cursos aligeirados, com carga horária mínima de 160 horas, concordando com a quantidade de matrículas acachapante na iniciativa privada em detrimento de cursos técnicos e ofertados no setor público como mostrado no quadro II.

Diante do exposto, com base nesses dados do número de desempregados no País desde 2012 a 2017, considerando que houve um recrudescimento gradual desde 2011, ano da implementação do Programa, até 2017, segundo o IBGE, atingido o patamar oficial de mais de $12 \%$ da população desocupada.

Considerando também que as ofertas entre a esfera pública e a privada, do montante divulgado no site do PRONATEC onde se afirmaque de 2011 a 2014, por meio do Programa, foram realizadas mais de 8,1 milhões de matrículas, entre cursos técnicos e de qualificação profissional, em mais de 4.300 municípios.

De acordo com a pesquisa de Melo e Moura (2016), a rede pública ofertou $46 \%$ dos técnicos, e apenas $10 \%$ dos cursos FIC, Já a privada, ofertou $54 \%$ dos cursos técnicos e $90 \%$ dos cursos FIC, o que caracterizou uma quase total terceirização da qualificação profissional pela iniciativa privada com o erário, e por fim, considerando que os recursos financeiros oriundos da contribuição coletiva (impostos pago por todos os brasileiros), do montante de 3.121 .867 bilhões de reais, destes, $80 \%$ financiaram os cursos FIC via Pronatec à iniciativa privada, principalmente no sistema $S$, sem citar os cursos técnicos.

Essas instituições detém a autonomia de como se deve qualificar/e ou formar o trabalhador brasileiro de acordo com as necessidades e interesses do setor produtivo, podendo instrumentalizar, sem a menor pretensão de elevação de escolaridade por meio dessa qualificação, preparar mão de obrapara o imediatismo do mercado ou deixar em disponibilidade a margem desse mesmomercado e sem nenhuma garantia de inserção no mundo do trabalho. 


\section{CONSIDERAÇÕES FINAIS}

A eficiência ou rentabilidade econômica esperada no Programa, considerando que esse critério examina a relação entre os custos despendidos e os resultados do Programa, cujos dados, são desconhecidos pelo fato de o governo não ter apresentado de forma transparente, nenhuma avaliação real e efetiva do Programa nos meios de comunicação oficiais ou extra oficiais, o que demandou muitas críticas.

Dentre essas críticas sobre a falta de avaliação e controle nos resultados do Programa, três anos após a implantação, Souza (2014), publica reportagem em site de notícias na internet com a seguinte matéria:

Governo não sabe quantos alunos conseguiram emprego após curso do Pronatec. [...]. O objetivo do Pronatec é capacitar jovens e adultos para aumentar sua empregabilidade. Até o final de 2014, o governo prevê o desembolso de 14 bilhões, porém, o MEC e o MTE (Ministério do Trabalho e Emprego) não foram capazes de informar qual a porcentagem de alunos conseguiu um emprego após a capacitação. ${ }^{7}$

Isso denota queo governo na sua implementação, ignorou a realidade de escassez dos recursos (posto que, todos os recursos públicos, provenientes de arrecadação de tributos gerais, têm suas destinações definidas para determinadas áreas de acordo com as agendas das políticas e o planejamento governamental, logo, são finitos e escassos),os quais foram utilizados de forma desarticulada das necessidades e demandas reais, quando do montante de recursos de 3.121 .867 bilhões de reais, destes, $80 \%$ financiaram os cursos FIC via Pronatec à iniciativa privada, principalmente no sistema S, que ficou com $70,6 \%$ em detrimento de cursos técnicos na rede pública.

Dessa forma, ao priorizar a iniciativa privada com $80 \%$ dos recursos públicos, dinamizou o mercado de Educação profissional, e em particular, a qualificação profissional, em detrimento da educação pública, oferecendo

\footnotetext{
${ }^{7}$ Disponível em: https://educacao.uol.com.br/noticias/2014/06/30/governo-nao-sabe-quantosalunos-conseguem-emprego-apos-curso-do-pronatec.htm 
cursos aligeirados descolados totalmente de elevação de escolaridade, oferecidos de maneira desconectada com as contingências sócio econômicas do país, o que na prática significa para o trabalhador, apenas uma ilusão que o certificado possa melhorar sua condição de empregável.

Enquanto ao critério da eficácia, o qual consiste no grau em que os objetivos e metas foram alcançados no programa, este também se mostrou irrelevante do ponto de vista de seus resultados.

No tocante ao grande volume de transferência de recursos, priorizando a iniciativa privada em detrimento do público, em um movimento contrário o que estabelece seus objetivos com relação ao ensino médio público. Caso esses recursos fossem aplicados no ensino médio público e no técnico integrado, em que se contemplasse uma formação integral dos sujeitos, os benefícios a médio e longo prazo, tanto para os jovense trabalhadores e, por conseguinte, para a sociedade em geral, do ponto de vista do desenvolvimento social e econômico, seriam sobremaneira bem mais significativos.

Ou então, para os que optassem em escolher a inserção técnica no dito mercado de trabalho, poderia ter dado certo em alguns segmentos profissionais, se antes de sua implementação, tivesse sido identificada as demandas das empresas, tanto privadas quanto as públicas no que diz respeito à mão de obra especializada, alinhando o programa à realidade desse mercadovisando à inserção dos egressos cursistas.

$E$ por fim, no que se refere à efetividade, este critério para ser percebido satisfatoriamente por todos os destinatários ou usuários do programa, visto que seus efeitos decorrem da junção entre a eficiência e a eficácia, por extensão, também não foram alcançados no que se refere aos benefícios gerados para a população por meio da educação profissional no programa, sobretudo, para os principais destinatários: a classe trabalhadora e os desocupados desprovidos de atividades laborais.

Basta observar a taxa crescente de desocupados desde 2011, data de início do programa, o que contribui sobremaneira para o recrudescimento das desigualdades sociais e que também leva ao aumento da violência em suas várias expressões e, por conseguinte, ao elevado número de assassinatos, 
em que os jovens entre 15 e 29 anos, pretos ou pardos, do sexo masculino e morador da periferia, são as principais vítimas e algozes dessa mazela social, que na base, está à busca pela sobrevivência. Issodenota o estado de anomia social que vive o povo brasileiro na atualidade, entre outros fatores, decorrentes da falta de postos de trabalho e não de desqualificação ou de um suposto apagão de mão de obra em uma sociedade cindida em classes e de relações assimétricas entre trabalho e capital.

Diante do exposto, infere-se, portanto, como resultado da pesquisa avaliativa, a hipótese levantada é que Pronatec FIC não atendeu aos critérios da eficiência, da eficácia, tampouco da efetividade pelos motivos acima elencados, entre outras variáveis aqui não citadas.

Entretanto, essa avaliação não é estanque, pois se trata de construção de conhecimento acerca da realidade social que se apresenta a todo tempo dinâmica e complexa; além disso, há a possibilidade de intervenção de outras variáveis que são concorrentes ao programa analisado, caso haja continuidade do mesmo.

\section{REFERÊNCIAS}

ALVES, Giovani. Dimensões da restruturação produtiva. Ensaio de Sociologia do trabalho. $2^{\circ}$ ed. Disponível em: http://www.giovannialves.org/drp.pdf. Acesso em: 22/12/2017.

BRASIL. Pronatec. Disponível em: <http://portal.mec.gov.br/pronatec>. Acesso em: 07 dez. 2017.

BRASIL. Constituição da República Federativa do Brasil. Senado federal. Brasília 2015.

Discurso da Presidenta da República, Dilma Rousseff, durante cerimônia de lançamento do Programa Nacional de Acesso ao Ensino Técnico e ao Emprego. Disponível em: <http://www2.planalto.gov.br/acompanhe-oplanalto/discursos/discursos-da-residenta/discurso-da-presidenta-darepublica-dilma-rousseff-durante- cerimonia-de-lancamento-do-programanacional-de-acesso-ao-ensino-tecnico-e-ao-emprego>. Acesso em $21 \mathrm{dez}$. 2017.

Pronatec. Disponível em: http://portal.mec.gov.br/pronatec. Acesso em: 07/06/2017. 
Agência IBGE notícias. Disponível em:

<https://agenciadenoticias.ibge.gov.br/agencia-sala-de-imprensa/2013agencia-de-noticias/releases/19162-pnad-continua-taxa-de-desocupacao-ede-12-0-no-trimestre-encerrado-em-novembro.html>. Acesso em: 09 jan. 2018.

CASTRO, Rodrigo Batista de. Eficácia, Eficiência e Efetividade na Administração pública. EnAmpad.Salvador-BA,2006. Disponível em: <http://www.anpad.org.br/enanpad/2006/dwn/enanpad2006-apsa-1840.pdf>. Acesso: 04 jun. 2018.

CIAVATTA, Maria. A produção do conhecimento sobre a qualificação do campo da educação profissional e tecnológica; Revista Hollos. Natal, ano 32, Volume 6 (2016). Dossiê A produção do conhecimento em educação profissional - Plano Nacional de educação (2014-2024) (todos os artigos). Disponível em: <http://www2.ifrn.edu.br/ojs/index. php/HOLOS/issue/view/109>. Acesso: 16 dez. 2016.

FIDALGO, Fernando; MACHADO, Lucília. Dicionário da Educação Profissional. Belo Horizonte: NETE/SETASCAD, 2000.

FRIGOTTO, Gaudêncio. Ensino Médio e técnico profissional: disputa de concepções e precariedade. Le Monde Diplomatique Brasil, São Paulo, mar. 2013. Disponível em:

$<$ http://www.diplomatique.org.br/artigo.php?id=1384>. Acesso em: 10 jan. 2017.

DORENELLES, Rachel Pereira. Avaliação da Educação Profissional: um estudo sobre indicadores educacionais específicos. 138f. Dissertação. Faculdade de Educação, Universidade de Brasília, 2011.

DOURADO, Luiz Fernandes. A Reforma do estado e as Políticas de Formação de Professores nos anos 90. In: DOURADO, L. F.;PARO, V. H. (org). Políticas Públicas \& Educação Básica. São Paulo: Xamã, vol. 23, n. 80, p. 234-252, set. 2001.

MELO,Ticiane Gonçalves Sousa de. O pronatec e o processo de expansão e privatização da educação profissional. Dissertação de Mestrado em educação profissional - Instituto federal de Educação do Rio Grande do Norte. Rio Grande do Norte. 2015.

MELO,Ticiane Gonçalves Sousa de. MOURA, Dante Henrique. Programa Nacional de acesso ao ensino Técnico e Emprego (Pronatec): Expansão e privatização da Educação profissional. In: Revista Holos. Natal, Ano 32, Volume 6 (2016). Dossiê: A produção do conhecimento em educação profissional - Plano Nacional de Educação (2014-2024).

SANDRONI, Paulo. (Org.). Novíssimo dicionário de economia. São Paulo: Best Seller, 1999. 
SECCHI, Leonardo. Políticas Públicas. Conceitos, esquemas de análises, casos práticos. $2^{\circ}$ ed. São Paulo: Cencage Learning. 2014.

SILVA, Maria Ozanira da Silva e. Avaliação de políticas e programas sociais: aspectos conceituais e metodológicos. In: SILVA, Maria Ozanira da Silva e. Avaliação de Políticas e Programas Sociais: Teoria e prática. São Paulo: Ed. Veras, 2001.

SOUZA, Celina. Estado da arte em pesquisa em Políticas Públicas. Políticas públicas no Brasil: HOCHMAN, Gilberto; ARETCHE, Marta; MARQUES, Eduardo. (org). $1^{\circ} \mathrm{ed}$. Rio de Janeiro. Editora Fiocruz, 2007. 398 pp.

SOUZA, Marcelle. Governo não sabe quantos alunos conseguiram emprego após curso do Pronatec. Disponível em: <https://educacao.uol.com.br/noticias/2014/06/30/governo-nao-sabe-quantosalunos-conseguem-emprego-apos-curso-dopronatec.htm?cmpid=copiaecola>. Acesso: 15 out. 2018.

SCHULTZ, T.O Capital Humano: Investimento em educação e pesquisa. Trad. De Marco Aurélio de M. Matos. Rio de Janeiro. Zarhar, 1973. 